\title{
COMPLEJIZACIÓN DE LOS CAZADORES Y ReCOleCtORES EN CHIU CHIU, Río LoA Medio (NORTE DE CHILE)
}

\author{
Donald Jackson y Antonia Benavente ${ }^{1}$
}

\section{* Introducción}

Resumen

La secuencia ocupacional de la microcuenca de Chiu Chiu (norte de Chile), muestra significativos cambios en el patrón de asentamiento y conjuntos de artefactos en correlación con un intenso proceso de aridización hacia 6000 años AP. Una respuesta a estas condiciones ambientales desfavorables fue el emplazamiento de asentamientos más permanentes en ambientes lacustres estables. Este proceso va asociado a cambios económicos y sociales, que reflejan una incipiente complejidad social de las comunidades cazadoras recolectoras que habitaron el norte de Chile.

Palabras claves: cambios ambientales - complejidad social cazadores recolectores - norte de Chile.

\footnotetext{
Abstract

The occupational sequence of Chiu Chiu's microbasin (Northern Chile) demonstrates that the area experienced significant changes in settlement patterns and artifact complexes, in a period of intense desertification, around 6000 years BP. One of the local responses to climate change was to settle more permanently near stable lake environments. This process reflect the economic changes that mark the initial social complexity of hunter-gatherer societies in the region.

Key words: environmental change - social complexity hunter gatherers - north Chile.

Recibido: septiembre 2008. Aceptado: junio 2009.
}

Los Andes Meridionales representan un área de particular interés para el estudio de los procesos de complejización socioeconómica de las sociedades cazadoras recolectoras. La concurrencia de cambios climáticos y la circunscripción en un ambiente desértico, generaron respuestas sociales que implicaron la reestructuración del modo de vida cazador. En este sentido, la microcuenca de Chiu Chiu, un pequeño oasis situado en el curso medio del río Loa, en el norte árido de Chile, constituye un buen caso para reflexionar al respecto.

Estudios previos en las tierras altas de los Andes Centrales y Meridionales han mostrado que los cambios hacia las sociedades formativas se vinculan fuertemente con las prácticas de pastoreo más que con una dependencia agraria (Wheeler et al. 1977; Benavente 1981, 1982; Rick 1983; Cartajena 1993; Cartajena y Concha 1997; Olivera 1997; Aschero y Yacobaccio 1998-99; Núñez et al. 2006). Estas prácticas pastoralistas tienen sus antecedentes en las comunidades cazadoras andinas del Holoceno Tardío (Aschero y Yacobaccio 1998-99; Yacobaccio 2000; Lavallée 2006; Núñez et al. 2006) en coincidencia con el advenimiento de condiciones climáticas más húmedas.

No obstante lo anterior, es a partir del Holoceno Medio, cuando imperan condiciones climáticas regionalmente áridas y, por tanto, entre las sociedades cazadoras recolectoras comienzan a desarrollarse cambios sustantivos en el patrón de asentamiento, tecnología y subsistencia

1 Departamento de Antropología, Facultad de Ciencias Sociales, Universidad de Chile. Casilla 10115, Santiago, CHILE. Email: djackson@uchile.cl, abenavente@uchile.cl 
(Lavallée 2006), que ocurre un incipiente proceso de complejización de estas comunidades (Price y Brown 1985; Arnold 1996). Esta situación se puede constatar en la secuencia de ocupaciones humanas de la microcuenca de Chiu Chiu.

En este contexto, sintetizamos las condiciones ambientales del área de estudio, sus principales cambios a través del tiempo y la secuencia ocupacional de los cazadores recolectores en una escala espacial amplia. Posteriormente, se caracterizan las ocupaciones humanas del Holoceno Medio y Tardío en la microcuenca de Chiu Chiu, describiendo los procesos de cambio que llevan a una incipiente complejización social de los cazadores recolectores del curso medio del río Loa. Finalmente, se discuten estos procesos en un marco regional más amplio, incluyendo el sureste de la Puna de Atacama y el advenimiento del período Formativo.

\section{* Antecedentes ambientales y OCUPACIONES HUMANAS}

La microcuenca de Chiu Chiu se sitúa en el curso medio del río Loa y forma parte de la gran cuenca de Calama, a una altura de 2500 m.snm. Geomorfológicamente está delimitada por una extensa terraza calcárea de 20 $\mathrm{m}$, bajo la cual una segunda terraza de 6 a $8 \mathrm{~m}$ presenta depósitos estratificados finos que contienen moluscos y diatomeas. El labrado fluvial ha dejado pequeñas islas aterrazadas al interior de la microcuenca, la que ha sido vaciada por el sistema del río Loa (Figura 1).

El plano inferior de la cuenca se encuentra ligeramente inclinado hacia la confluencia de los ríos Loa y Salado, donde la avifauna es abundante $y$, por tanto, aprovecha el ambiente fluvial. Inmediatamente al norte de dicha confluencia, en las vegas de Chiu Chiu, predominan los pastos cortos y duros. La formación vegetal arbustiva es el jaral desértico compuesto principalmente por brea (Tessaria absionthiodes), cachiyuyo (Atriplexsp.), pingo pingo (Ephedrabreana) y rica rica (Acantholippia riojana), además de una significativa presencia de algarrobos (Prosopis sp.) y chañares (Geoffrea decorticans) característicos de la región (Orellana 1971; Serracino y Thomas 1971; Benavente 1981).

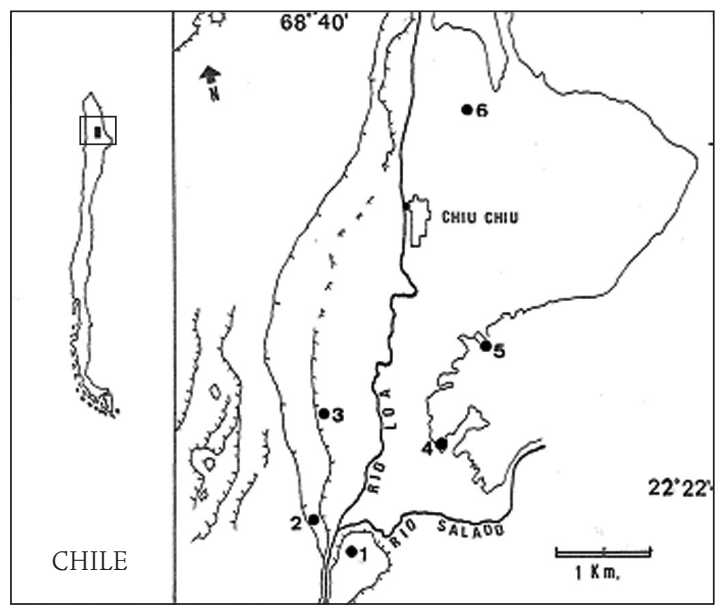

Figura 1. Ubicación de los sitios: 1) Isla Grande; 2) Confluencia 2;3) Loa Oeste 3;4) Confluencia 1;5) Cementerio Chiu Chiu, y 6) Chiu Chiu 200 en la microcuenca de Chiu Chiu, en el curso medio del río Loa.

Las condiciones paleoambientales registradas en los sedimentos de lagos y salares en el altiplano de la Puna de Atacama fueron más húmedas que las actuales durante finales del Pleistoceno y el Holoceno Temprano, entre 12800 y 8100 AP (Grosjean 1994; Grosjean y Núñez 1994; Betancourt et al. 2000; Rech et al. 2002). Durante el Holoceno Medio (8000-3500 AP) habrían imperado condiciones de extrema aridez (Núñez et al. 1995-96, 1999; Grosjean et al. 1997, 2003), aunque algunos estudios de paleomadrigueras sugieren condiciones húmedas durante este período (Betancourt et al. 2000). Esta aparente contradicción podría reflejar condiciones zonales específicas, o bien, el grado de resolución temporal y espacial de los distintos archivos paleoambientales (Grosjean et al. 2003). Hacia el Holoceno Tardío (ca.3500-3000 AP), se habrían reanudado las condiciones más húmedas (Núñez et al. 1999), favoreciendo regionalmente algunos ambientes para las ocupaciones humanas.

Así, aunque Chiu Chiu es una antigua cuenca lacustre que debió constituir un ambiente atractivo para la megafauna pleistocénica, como lo atestiguan los efímeros hallazgos de fauna extinta (Orellana 1965), aún no se han constatado evidencias de ocupaciones humanas finipleistocénicas. 
Sin embargo, en el salar de Punta Negra situado en el extremo meridional de la Puna de Atacama, a 3000 m.snm, se ha registrado una ocupación temprana correspondiente a grupos paleoindios en lo que fue el borde de un paleopantano (Grosjean et al. 2005). Por otra parte, en un pequeño abrigo rocoso denominado Tuina 5 , situado en una quebrada de pie de Puna, a $2800 \mathrm{~m} . \mathrm{snm}$, se ha identificado una efímera presencia de cazadores del Holoceno Temprano, con puntas triangulares y otros artefactos unifaciales vinculados a restos de fauna moderna y a un sacro de Equidae extinto (Núñez et al. 2002).

Estas evidencias sugerirían un sincronismo y coexistencia en estos ambientes, de cazadores de fauna extinta con puntas "cola de pescado", con otros de tradición arcaica temprana portadores de puntas triangulares tipo Tuina (Núñez et al. 2001).

Si bien aún no se han registrado evidencias de ocupaciones del Arcaico Temprano en Chiu Chiu, éstas se encuentran bien representadas en la Puna Salada, durante las fases Tuina y Tambillo (Núñez 1992). Ambas fases corresponderían a cazadores recolectores que se habrían asentado principalmente bajo aleros rocosos, portadores de puntas de proyectiles triangulares de base ligeramente cóncava, raspadores de dorso alto, raederas, lascas utilizadas y yunques, entre otros artefactos, asociados a fogones, restos de camélidos y a varias especies de roedores.

Estos grupos habrían tenido un patrón de movilidad moderado no regularizado de tipo trashumántico inicial, circunscrito a la vertiente occidental de la Puna atacameña, con énfasis en la ocupación de pisos altos 3500 $\mathrm{m} . \mathrm{snm})$, especialmente de hábitat de quebradas intermedias (Núñez y Santoro 1988).

La presencia de ocupaciones del Arcaico Temprano en los aleros de Tuina 1 y 5 situados en las serranías de Calama (Núñez y Santoro 1988; Núñez et al. 2002), y en los aleros Chulqui I (Sinclaire 1985; De Souza 2004), Toconce (Aldunate et al.1986; De Souza 2004) y El Pescador (De Souza 2004), localizados en la cuenca alta del río Salado, en la región del Loa Superior, debieran suponer algún tipo de movimiento esporádico y estacional de grupos de cazadores recolectores hacia la microcuenca de Chiu Chiu. Sin embargo, aún no se han registrado evidencias arqueológicas que avalen esta suposición.

\section{* La secuencia ocupacional en la MICROCUENCA DE CHIU CHIU}

En la microcuenca de Chiu Chiu (Tabla 1), las primeras ocupaciones humanas se remontarían al Holoceno Medio, cuando en la región imperaban condiciones de extrema aridez (Núñez et al. 1995-96; Grosjean et al. 1997, 2003), concentrándose en "ecorrefugios" (Núñez et al. 1999). Por sus particulares características geomorfológicas, en estos lugares se mantuvieron condiciones ambientales más favorables, permitiendo la existencia de lagunas y vegas semipermanentes entre 7000 y 3000 años $C^{14}$ AP (Núñez et al. 1999). Una situación similar debió ocurrir en las proximidades de la confluencia de los ríos Loa y Salado, motivando las primeras ocupaciones humanas en la microcuenca de Chiu Chiu, identificadas en los asentamientos Confluencia 2 e Isla Grande.

\section{Confluencia 2 e Isla Grande}

El asentamiento Confluencia 2 se sitúa $7 \mathrm{~km}$ al suroeste del actual pueblo de Chiu Chiu, en el borde de una terraza fluvial de aproximadamente $20 \mathrm{~m}$ de altura, y a unos $300 \mathrm{~m}$ de la confluencia de los ríos Loa y Salado (Orellana 1965). Es un extenso campamento de cerca de $1000 \mathrm{~m}^{2}$ (Figura 2) identificado por el abundante material lítico en superficie, asociado a sectores oscuros (debido a la actividad de combustión) y a depresiones y suaves montículos de basura, que varían de 2 a $4 \mathrm{~m}$ de diámetro, que han sido interpretados como recintos habitacionales semisubterráneos (Orellana 1965; Jackson 1993-94). Una datación radiocarbónica obtenida por Lanning dio un resultado de $5880 \pm 130$ años AP (cit. en Núñez 1976).

Las excavaciones estratigráficas de dos cuadrículas de $2 \times 2$ m en un área con depresiones, atestiguaron la presencia de una habitación semisubterránea socavada en el calcáreo estéril, aprovechando las irregularidades de éste, que también sirvieron para disponer al menos dos fogones delimitados con algunas rocas. Al interior de éstos se registró abundante material orgánico, astillas y huesos de camélidos, así como algunos implementos líticos. Cerca de las estructuras de combustión se detectaron carbones y cenizas asociados a un fragmento de mortero, indicando un área de actividad doméstica vinculada a la preparación y consumo de alimentos y el posterior descarte de restos 
óseos, algunos de los cuales al interior de los fogones, junto con fragmentos de ramitas y bejucos parcialmente carbonizados, sugieren su empleo como material de combustión (Jackson 1993-94).

Las evidencias de fauna registradas incluyen un total de 349 restos óseos de aves y camélidos. Los camélidos están representados por huesos de las extremidades y en menor proporción, de vértebras, costillas y del cráneo, algunos con huellas de corte producto del procesamiento secundario. Un $46.41 \%$ de los huesos presenta indicios de calcinación. La gran mayoría de estos restos están fracturados y con huellas de impactos intencionales, lo que sugiere la extracción de la médula para su consumo y su posterior descarte en los fogones, siendo aprovechados como material de combustión (Benavente $1989 \mathrm{Ms}$ ).
Otras evidencias culturales están constituidas por cuentas discoidales elaboradas sobre valvas de moluscos marinos procedentes del Pacífico, restos de cuero, plumas y algunos trozos de vellones de pelos, probablemente de camélidos (Jackson 1993-94; Jackson y Benavente 1994).

El instrumental lítico (Figura 3) está representado por 96\% de derivados de núcleo (lascas $93.89 \%$ y láminas $2.09 \%$ ), mientras que el resto del material (4\%) corresponde a núcleos, preformas e instrumentos. Las puntas de proyectiles son de forma lanceolada apedunculada o con pedúnculo enunciado; hay cuchillos sobre puntas retomadas y cuchillos discoidales, raspadores convexos y cóncavos (muescas), además de piezas con desprendimientos bipolares (icuñas?), lascas con golpes de buril e implementos de molienda que incluyen manos de moler circulares y morteros de superficie cónica.

\begin{tabular}{|c|c|c|c|c|c|c|}
\hline Sitios & Fechas AP & Fechas AC & Laboratorio & Muestra & Período & Referencias \\
\hline Isla Grande & $6080 \pm ?$ & $4130 \pm ?$ & $?$ & Carbón & Arcaico Medio & Núñez 1976 \\
\hline Confluencia 2 & $5880 \pm 130$ & $3930 \pm 130$ & $?$ & Carbón & Arcaico Medio & Núñez 1976 \\
\hline Loa Oeste 3 & ? & $?$ & - & - & Arcaico Tardío? & Orellana 1971 \\
\hline Confluencia 1 & $?$ & $?$ & - & - & Arcaico Tardío & Serracino y Thomas 1971 \\
\hline RanL-92 & $4565 \pm 110$ & $2615 \pm 110$ & $\mathrm{I}-7017$ & Carbón & Arcaico Tardío & Druss 1978 \\
\hline RanL-140 & $4530 \pm 110$ & $2580 \pm 110$ & $?$ & $?$ & Arcaico Tardío & Druss 1978 \\
\hline RanL-15140 & $4500 \pm 116$ & $2550 \pm 116$ & $?$ & Carbón & Arcaico Tardío & Druss 1978 \\
\hline RanL-92 & $4280 \pm 170$ & $2330 \pm 170$ & $\mathrm{I}-7017$ & Carbón & Arcaico Tardío & Druss 1978 \\
\hline RanL-133A & $4250 \pm 105$ & $2300 \pm 105$ & $\mathrm{I}-5173$ & Carbón & Arcaico Tardío & Druss 1978 \\
\hline RanL-4 (A)* & $4115 \pm 105$ & $2165 \pm 105$ & $\mathrm{I}-6741$ & Apatita & Arcaico Tardío & Druss 1978 \\
\hline RanL-104 (B) & $4050 \pm 105$ & $2100 \pm 105$ & $?$ & $?$ & Arcaico Tardío & Druss 1978 \\
\hline RanL-118 & $3675 \pm 470$ & $1725 \pm 470$ & $\mathrm{I}-7016$ & Carbón & Arcaico Tardío & Druss 1978 \\
\hline RanL-2-76 (A) & $3625 \pm 85$ & $1675 \pm 85$ & I-70016 & Carbón & Arcaico Tardío & Druss 1978 \\
\hline Chiu Chiu 200 & $2950 \pm 310$ & $1000 \pm 310$ & PUC $^{* \star}$ & Cerámica & Formativo & Benavente 1982 \\
\hline Chiu Chiu 200 & $2950 \pm 300$ & $1000 \pm 310$ & PUC $^{* \star}$ & Cerámica & Formativo & Benavente 1982 \\
\hline Chiu Chiu 200 & $2780 \pm 300$ & $920 \pm 300$ & PUC $^{\star *}$ & Cerámica & Formativo & Benavente 1982 \\
\hline Chiu Chiu 200 & $2850 \pm 260$ & $900 \pm 260$ & PUC $^{\star \star *}$ & Cerámica & Formativo & Benavente 1982 \\
\hline
\end{tabular}

Tabla 1. Dataciones $C^{14}$ (no calibradas) y TL obtenidas para sitios del Arcaico Medio, Tardío y Formativo Temprano ( ${ }^{*}$ Cementerio Chiu Chiu; ${ }^{* *}$ Pontificia Universidad Católica de Chile). 
Las materias primas utilizadas son: sílex lechoso ( $91.39 \%)$, basalto $(5.34 \%)$, pedernal $(0.21 \%)$, obsidiana (0.17\%), cuarzo (0.4\%) y otras no identificadas $(2.82 \%)$. Se han distinguido las materias primas locales de las no locales sobre la base de una distancia de $40 \mathrm{~km}$ (Meltzer 1989). Así, rocas locales como el basalto, proceden probablemente de fuentes ubicadas a unos $30 \mathrm{~km}$ del río Loa (Druss 1976). El sílex lechoso fue obtenido localmente de la cantera-taller de Talabre, situada a solo unos $4 \mathrm{~km}$ al noroeste del sitio, mientras que el cuarzo, pedernal y otras rocas no identificadas posiblemente se obtuvieron en la propia cuenca de Chiu Chiu o en sus proximidades. La obsidiana sería la única materia prima no local, procedente probablemente de fuentes ubicadas en la alta Puna, sugiriendo una movilidad trashumántica. Es posible, todas las materias primas con excepción del sílex lechoso se obtuvieron en el marco de una estrategia "inserta" (Binford 1979) y seguramente provienen de fuentes no localizadas (Gould y Saggers 1985).

Funcionalmente las categorías identificadas indican actividades de caza y destazamiento de presas, de acuerdo a la alta presencia de puntas de proyectiles, cuchillos y raederas. Otras categorías instrumentales representadas por tajadores, raspadores, cuchillos y buriles sugieren actividades de manufactura. Los escasos implementos para moler señalan una disminuida actividad de recolección y molienda de vegetales.

La alta frecuencia de desechos en relación con una baja presencia de núcleos, supone el transporte de instrumentos terminados o en proceso de elaboración (preformas) desde la cantera-taller de Talabre, así como el traslado de un gran número de derivados de núcleos utilizados como instrumentos de filos vivos (Jackson 1993-94; Jackson y Benavente 1994). Muchos desechos pueden ser considerados subproductos del rebaje de preformas y reactivado de filos desgastados. En general, el instrumental tiende a ser más formal que informal (Andrefsky 1998) y las cadenas operativas están mejor representadas para las fases finales del proceso de producción.

En suma, las características de este sitio demuestran claramente que estamos frente a un campamento base, de naturaleza residencial de larga estadía, con uno o más

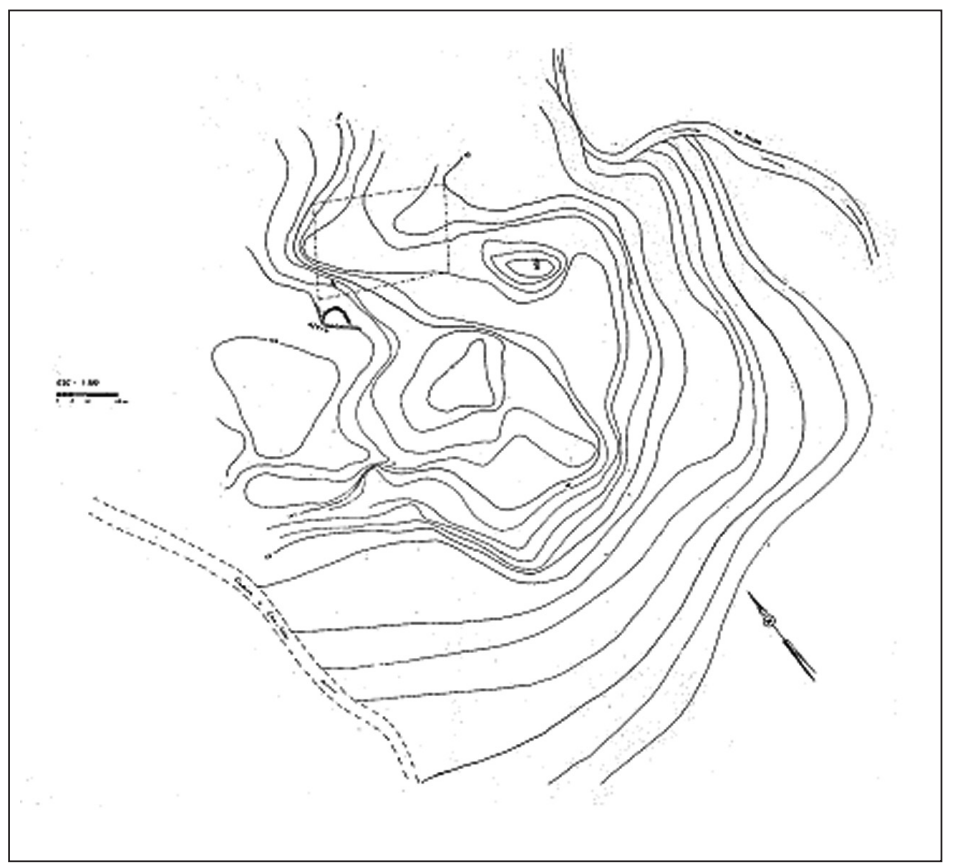

Figura 2. Topografía del sitio Confluencia 2. Plano modificado de Orellana (1965). 
eventos ocupacionales, donde se realizaron diversas actividades domésticas, además del procesamiento, uso, mantenimiento y descarte del instrumental lítico.

Por otra parte, a solo un par de kilómetros al sureste de Confluencia 2 se emplaza el sitio Isla Grande. Al igual que aquél, es un extenso campamento de base residencial con contextos y conjuntos artefactuales similares (puntas lanceoladas, implementos de molienda, algunos restos vegetales y abundantes restos de camélidos; Núñez 1983). Posee una datación radiocarbónica de 6080 AP (Núñez 1976).

Isla Grande es la primera ocupación de cazadores recolectores del Arcaico Medio en la microcuenca de Chiu Chiu. Le sigue Confluencia 2 en sincronía, probablemente, con sus últimos momentos ocupacionales. Se trataría de grupos cazadores con un patrón de movilidad trashumántica, que descienden desde las serranías del Loa, y tal vez desde la alta Puna, a ambientes más templados, aprovechando la concentración y permanencia de recursos fluviales y animales (camélidos) en la microcuenca de Chiu Chiu. Esta última actuaría como "ecorrefugio" en momentos que en la región imperaban condiciones áridas (Núñez 1983; Jackson y Benavente 1994).

\section{Loa Oeste 3 y Confluencia 1}

El sitio Loa Oeste 3 se localiza a unos $3.5 \mathrm{~km}$ al oeste del río Loa, en el talud de la terraza fluvial a unos $12 \mathrm{~m}$ de su cornisa. Las excavaciones permitieron distinguir cinco capas correspondientes probablemente a tres eventos ocupacionales asignables a grupos cazadores recolectores (Orellana 1971).

Estos grupos aprovecharon las irregularidades de la superficie calcárea de manera similar que en Confluencia 2 para construir sus habitaciones semisubterráneas. En la ocupación intermedia se construyó una estructura circular pircada y socavada en el calcáreo. Asociados a estas estructuras hay densos basureros constituidos por desechos e instrumentos líticos, abundantes restos óseos de camélidos, roedores, algunos instrumentos de hueso (retocadores) y restos de moluscos procedentes del Pacífico.

Por otra parte, sobre la estructura pircada se registró el entierro de un individuo femenino dolicoide en posición flec-

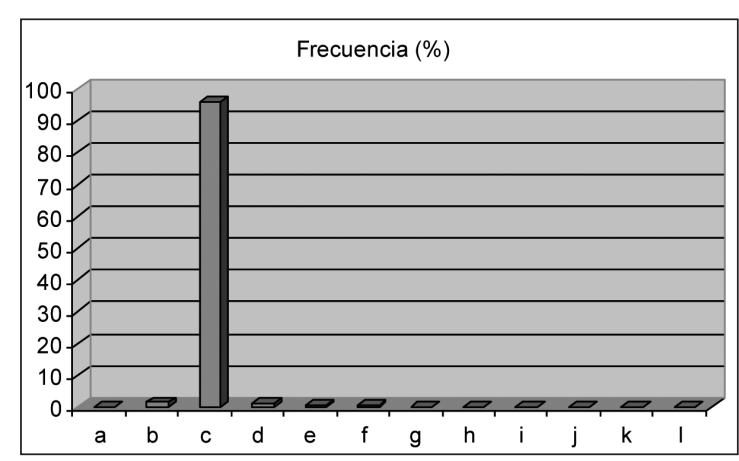

Figura 3. a) Guijarros astillados (5); b) Núcleos (68); c) Derivados de núcleos (4817); d) Lascas y láminas modificadas (65); e) Preformas bifaciales (32);f) Puntas de proyectiles (11);g) $\mathrm{Cu}$ chillos (7); h) Raederas (2); i) Raspadores (4); j) Tajadores (1);

k) Percutores (1);1) Implementos de molienda (2).

tada, con el cráneo direccionado hacia el oeste y cubierto por varias concreciones de calcáreo y un mortero. Debajo de este entierro aparecieron grandes piedras $(50 \times 40 \mathrm{~cm})$ dispuestas verticalmente unas al lado de otras formando parte de la estructura pircada circular, asociada a un estrato carbonoso y a desechos domésticos (Orellana 1971).

El instrumental lítico muestra una significativa preponderancia de derivados de núcleos y desechos respecto a las restantes categorías identificadas, la que a su vez no se corresponde con la baja frecuencia de núcleos. Esto sugiere el transporte de preformas y derivados de núcleo al campamento, en donde fueron terminados, mientras que los derivados de núcleo fueron utilizados como matrices e instrumentos de filos vivos. Lo anterior muestra una cadena operativa representada fundamentalmente por las fases finales de elaboración y el reactivado de filos desgastados.

En cuanto a las materias primas, aunque desconocemos su frecuencia, sabemos que se utilizó el sílex lechoso, el basalto, el cuarzo y otras rocas no identificadas. Probablemente, el aprovisionamiento de éstas siguió un patrón similar al practicado en Confluencia 2.

En este contexto también tienden a dominar los instrumentos formales sobre los informales (Andrefsky 1998). Las categorías identificadas incluyen puntas de proyectiles y preformas lanceoladas apedunculadas, raspadores convexos, raederas elaboradas sobre lascas y microperforadores, percutores, sobadores e implementos de molienda que incluyen manos de moler circulares y morteros cónicos. 
En suma, Loa Oeste 3 puede ser interpretado como un amplio campamento de base residencial, con estructuras habitacionales más estables y permanentes que aquellas de Confluencia 2 e Isla Grande, predominando las actividades de caza y recolección en un contexto doméstico. A diferencia de los sitios mencionados, las puntas de proyectiles son apedunculadas y algo más pequeñas, registrándose nuevas categorías instrumentales como los microperforadores que destacan como particulares de este sitio.

Por otra parte, Confluencia 1 se sitúa a unos $400 \mathrm{~m}$ al este de la confluencia de los ríos Loa y Salado, en un remanente o islote de la terraza fluvial con una altura aproximada de $18 \mathrm{~m}$. Este asentamiento se identifica por una amplia extensión superficial de material lítico en un área de $1500 \mathrm{~m}^{2}$, lo que llevó inicialmente a pensar que se trataba de un taller lítico (Orellana 1965). No obstante, la presencia de estructuras, fogones, basureros e implementos de molienda, permitió definirlo con posterioridad como un campamento habitacional (Serracino y Thomas 1971).

Su intervención estratigráfica permitió identificar una secuencia de cinco capas que probablemente pueden ser el resultado de tres eventos ocupacionales. Una estructura pircada en los niveles superiores, indica que era un campamento habitacional asociado a abundantes basuras que se inician en los niveles inferiores. Estas basuras están constituidas por material lítico y restos óseos de camélidos, aves y roedores, distribuidos muy homogéneamente a lo largo de la secuencia estratigráfica. Otros restos culturales incluyen pequeños guijarros ovoidales, cuentas de collar, fragmentos de conchas marinas, restos de plumas, lana, vegetales $y$ trozos de ocre.

Los instrumentos líticos (Figura 4), están constituidos fundamentalmente por derivados de núcleo, desechos de talla y una escasa presencia de núcleos (Orellana 1965). Las categorías identificadas corresponden a instrumentos sobre lascas y láminas retocadas interpretadas como cuchillos, raederas e instrumentos en proceso, puntas de proyectiles lanceoladas apedunculadas, gran abundancia de varios tipos de microperforadores, implementos de molienda, machacadores y sobadores (Serracino y Thomas 1971).

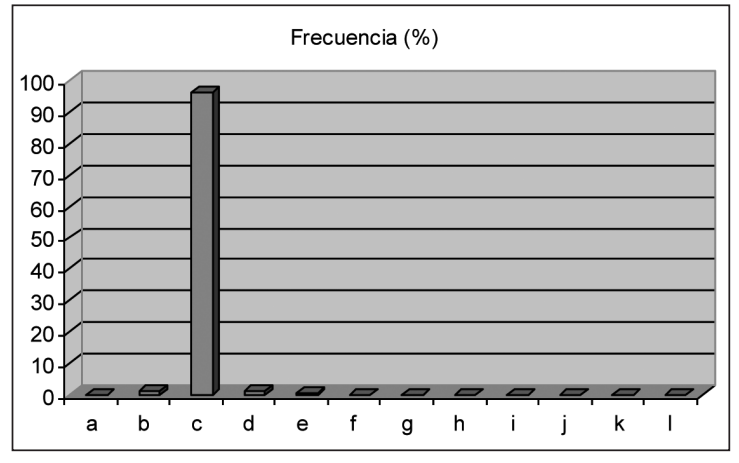

Figura 4. a) Derivados de núcleos y desechos (8849); b) Instrumentos sobre lascas (40); c) Instrumentos sobre láminas (121); d) Bifaciales (166); e) Perforadores (304); f) Implementos de molienda (17).

Las materias primas utilizadas provienen de fuentes locales: sílex, cuarzo, riolita y basalto. El cuarzo se utilizó fundamentalmente para la producción de perforadores, mientras que el sílex para las piezas bifaciales, especialmente puntas de proyectiles.

En el sitio están representadas fundamentalmente las fases finales de producción de instrumentos a partir de lascas, láminas y matrices, las que son transportadas desde las canteras. El proceso de producción se orientó a la elaboración de perforadores; no obstante, las cuentas de collar son escasas (10 ejemplares), lo que podría estar sugiriendo una producción de bienes de prestigio para intercambio, como ocurre posteriormente en el período Formativo en la subregión del río Salado (Rees y De Souza 2004).

Los restos óseos incluyen algunos muy fragmentados de camélidos, aves y roedores (Figura 5), que tienen una distribución muy homogénea a lo largo de la secuencia estratigráfica, mostrando una actividad prioritaria de caza de camélidos y, en menor medida, de aves y roedores.

En suma, Confluencia 1 corresponde a un campamento habitacional al igual que Loa Oeste 3. No obstante, cronológicamente es algo más tardío a juzgar por una mayor representación de microperforadores (Serracino y Thomas 1971), como ocurre en los sitios del Complejo Chiu Chiu (Druss 1976). La ocupación es también más consistente que en Loa Oeste 3, sugiriendo mayor estabilidad y permanencia. 
Ambos sitios representan los inicios del Complejo Chiu Chiu y, contrariamente a lo que sugeríamos en años anteriores (Jackson y Benavente 1994), no tienen una relación de continuidad -al menos tecnológica- con los componentes de Isla Grande y Confluencia 2. Estos sitios no presentan una industria de microperforadores y sus puntas de proyectiles son lanceoladas con pedúnculo enunciado, estando ausentes en Loa Oeste 3 y Confluencia 1. En síntesis, se trata de grupos de cazadores de camélidos, con campamentos más estables, estructurados de forma distinta a aquellos del Holoceno Medio.

\section{Cementerio Chiu Chiu (RanL-1-4A)}

Este sitio, que forma parte del Complejo Chiu Chiu (Druss 1976), corresponde a un extenso asentamiento localizado a solo un par de kilómetros al sureste del actual pueblo de Chiu Chiu en los remanentes de una terraza fluvial de unos $18 \mathrm{~m}$ de altura. Se ha datado hacia 4115 \pm 105 años AP (Druss 1976), y tiene gran relevancia debido a su estructuración espacial. En efecto, presenta varios sectores habitacionales domésticos en una extensión aproximada de $60000 \mathrm{~m}^{2}$ (Figura 6), con un sector habitacional central y más extenso, al cual se agrega un segundo sector menos denso, constituido por varias áreas habitacionales asociadas a actividades de procesamiento de instrumentos líticos (Jackson 1990 Ms; Ferraz 1991).

El sector central presenta un aglutinamiento de montículos de basura, los que al ser excavados parcialmente (39) $\mathrm{m}^{2}$ ), expusieron una gran estructura habitacional identificada por un muro pircado, con densos depósitos de basura adosados. Este muro aumenta de altura a medida que baja la pendiente del terreno. Los montículos de basura

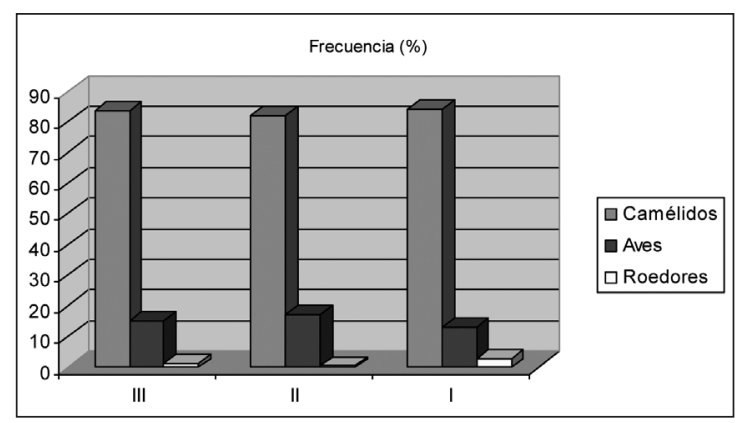

Figura 5. Frecuencia de restos óseos en el sitio Confluencia 1. sugieren la presencia de varias estructuras habitacionales semicirculares siguiendo un patrón aglutinado. El piso ocupacional se encuentra compactado y aunque no se registraron fogones, sí se detectaron pequeños lentes de ceniza que podrían corresponder a actividades de limpieza.

Los basureros cubren los recintos habitacionales y los desechos están constituidos fundamentalmente por instrumental lítico, restos óseos especialmente de camélidos, restos de textiles, cordelería, cuentas de collar elaboradas en concha, moluscos (Oliva peruviana, Argopecten purpuratus, Concholepa concholepa, Eurhomalea lenticulares, Choromitylus chorus y Fissurella sp.), además de miniaturas líticas zoomorfas pulimentadas, instrumentos de hueso, restos de vegetales y un palo cavador.

Asociadas a los depósitos de basura se identificaron algunas osamentas humanas en contexto secundario, correspondientes a dos individuos adultos jóvenes de ambos sexos (Ferraz 1991; Cartajena 1993).

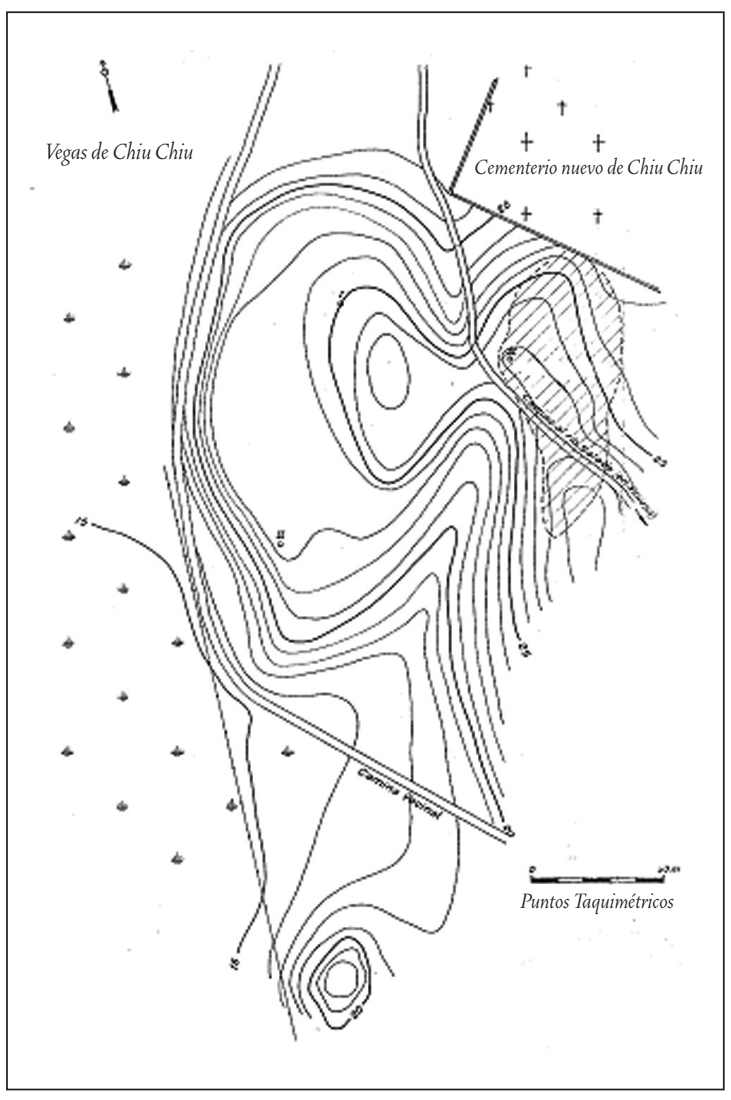

Figura 6. Topografía del Cementerio Chiu Chiu. Plano modificado de Gómez (1963). 
En el segundo sector situado al oeste del primero, con vista a la cuenca de Chiu Chiu, se registran extensas áreas de procesamiento de instrumentos líticos así como varias estructuras habitacionales, de las cuales, dos de tipo semisubterráneo fueron intervenidas estratigráficamente. En una de ellas se registró un contexto con puntas de proyectiles, cuchillos-raederas, raspadores convexos, muescas, perforadores y microperforadores, núcleos, derivados de núcleos entre otros desechos; así como restos óseos de camélidos, de aves y roedores, también moluscos y restos de peces del Pacífico, plumas y partículas de carbón. En otra de estas estructuras se registró el entierro de un individuo con posible deformación craneana (Jackson y Benavente 1994). Varias de estas estructuras fueron reocupadas parcialmente con posterioridad al abandono del sitio.

El instrumental lítico en el sector central del asentamiento (Figura 7), está constituido por una mayor frecuencia de derivados de núcleo y desechos de talla consistente con la alta frecuencia de núcleos e instrumentos procesados, que incluyen preformas y fragmentos de artefactos en proceso de elaboración, puntas de proyectiles lanceoladas apedunculadas pequeñas, cuchillos y raederas sobre lascas retocadas, raspadores convexos, perforadores microlíticos e implementos de molienda correspondientes a manos ovoidales y fragmentos de molinos (Ferraz 1991). Otras categorías cuantificadas son yunques $(n=1)$, percutores $(n=27)$, alisadores $(n=1)$, guijarros con pigmento $(n=1)$ y piedras horadadas $(n=4)$.

Las materias primas utilizadas, de acuerdo a su frecuencia, son: sílex, cuarzo, andesita, cuarzo lechoso, jaspe, basalto, toba, obsidiana, granito y otras no identificadas, además de piedra pómez, las que corresponden a fuentes de aprovisionamiento locales y no locales. Gran parte de la cadena operativa se encuentra bien representada en sus distintas etapas de elaboración.

Los restos óseos corresponden a 3250 fragmentos de camélidos, entre los que se cuentan especies silvestres y domésticas incluyendo cuatro guanacos, una vicuña y tres llamas, predominando los especímenes adultos. Un alto porcentaje de estos restos se encuentran quemados (30\%) y altamente fragmentados (Cartajena 1993).
Entre la basura también se encontraron vellones, trozos de pieles, hilados y algunos restos de cestería y textiles como la "pelliza", es decir piezas constituidas por la unión estructural de fibras vegetales, algunas plumas y principalmente vellones y pieles de distinto origen animal. Además, se encontraron ocho fragmentos de tejido anillado con enlace simple en " 8 " y enlace simple en "ojal", tejidos de nudo de doble enlace y tejido plano 1:1 (o ligamento tela). Para la "pelliza" se utilizó probablemente piel de roedores, además de fanéreos de vicuña, llama y guanaco, que también fueron utilizados como materia prima para las otras formas textiles (Arias et al. 1991)

Los contextos y artefactos de este asentamiento permiten afirmar que se trata de un campamento base residencial de grupos cazadores recolectores con mayor permanencia en la microcuenca de Chiu Chiu, que manifiesta claros indicios de un incipiente proceso de complejización económica y social. Esto se evidencia por la presencia de animales domésticos, tecnología de cestería y textiles, así como por un patrón bien estructurado de habitaciones aglutinadas a modo de una emergente aldea.

\section{* Discusión y CONClusiones}

Las primeras ocupaciones de la microcuenca de Chiu Chiu, Isla Grande y Confluencia 2, no muestran afinidades tipológicas con los componentes del Arcaico Temprano de las fases Tuina y Tambillo (Núñez y Santoro 1988). Representan a grupos distintos y más tardíos que se establecen en el borde de la microcuen-

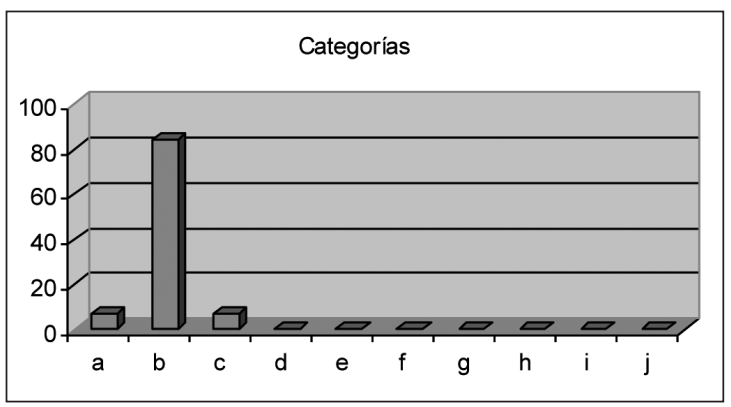

Figura 7.a) Núcleos (763); b) Derivados de núcleos y desechos (8820); c) Preformas (704); d) Bifaciales (23); e) Cuchillos (32);f) Raederas (17);g) Raspadores (23); h) Perforadores (63); i) Fragmentos retocados $(14) ; \mathbf{j}$ ) Implementos de molienda (35). 


\begin{tabular}{|l|c|c|c|c|c|c|c|}
\hline Sitios & Período & Emplazamiento & Extensión & Depósito & Habitaciones & Entierros & Ocupaciones \\
\hline Isla Grande & Arcaico Medio & Terraza superior & $i ?$ & $i ?$ & No pircadas & No & Estacional reiterada \\
\hline Confluencia 2 & Arcaico Medio & Terraza superior & $1000 \mathrm{~m}^{2}$ & $30 \mathrm{~cm}$ & No pircadas & No & Estacional reiterada \\
\hline Loa Oeste 3 & Arcaico Tardío & Talud Terraza sup. & $1200 \mathrm{~m}^{2}$ & $120 \mathrm{~cm}$ & Pircadas & Sí & Semipermanente \\
\hline Confluencia 1 & Arcaico Tardío & Terraza inferior & $1500 \mathrm{~m}^{2}$ & $100 \mathrm{~cm}$ & Pircadas & No & Semipermanente \\
\hline Cementerio Chiu Chiu & Arcaico Tardío & Terraza inferior & $60000 \mathrm{~m}^{2}$ & $80 \mathrm{~cm}$ & Pircadas & Sí & Semipermanente \\
\hline Chiu Chiu 200 & Formativo & Terraza inferior & $28693 \mathrm{~m}^{2}$ & $75 \mathrm{~cm}$ & Pircadas & No & Semipermanente \\
\hline
\end{tabular}

Tabla 2. Caracterización de los campamentos residenciales del Arcaico Medio-Tardío y Formativo Temprano.

ca mencionada, en un ambiente de oasis más estable y óptimo para el asentamiento, en momentos en que en la región imperaban condiciones climáticas áridas (Núñez et al. 1995-96, 1999, 2001, 2002). Componentes líticos similares a Confluencia 2, registrados en el sitio La Damiana (situado a 3100 m.snm y a unos 8 $\mathrm{km}$ aguas arriba de la confluencia de los ríos Loa y San Pedro) sugieren una localización similar de los asentamientos en "ecorrefugios", generando una mayor territorialidad (De Souza 2004).

Estos grupos cazadores se asientan hacia $6000 \mathrm{AP}$, próximos a la confluencia de los ríos Loa y Salado, en un ambiente lacustre asociado a pequeñas vegas que concentraba una abundante avifauna y variados recursos vegetales. La localización de estos asentamientos privilegió los bordes de la cota alta de la terraza fluvial más antigua, teniendo una amplia visibilidad de gran parte de la cuenca; estrategia que es coherente con prácticas cinegéticas que requerían monitorear las tropillas de guanacos y otros recursos (Tabla 2).

La estructura de estos campamentos tiene un desarrollo más horizontal que vertical, correspondiente probablemente a varias viviendas de una misma banda. Se aprovecharon las irregularidades del terreno para socavar pequeñas estructuras habitacionales semisubterráneas de planta circular. Las basuras se acumularon esencialmente en el exterior generando un borde pronunciado, que posi- blemente sirvió de sostén adicional a las estructuras. Esto generó leves montículos que rodean delimitando y acentuando la profundidad de las habitaciones. Al interior de las estructuras, se aprovecharon oquedades del calcáreo y trozos de éste para acondicionar pequeños fogones, junto a los cuales se depositaron artefactos descartados y algunas basuras correspondientes básicamente a restos óseos.

El instrumental lítico muestra para ambos sitios una tecnología más orientada a las actividades de caza que a la recolección, como lo atestiguan los restos óseos de roedores, aves, y especialmente, camélidos. El procesamiento del instrumental lítico está representado principalmente por las fases finales de la cadena operativa, que incluye el rebaje de preformas bifaciales, la terminación de otros instrumentos, el retomado de piezas fracturadas y el reactivado de filos desgastados. Se trata de una estrategia tecnológica conservada (Nelson 1991), en la cual predominó una industria de preformas bifaciales elaboradas en la cercana cantera-taller de Talabre que proporcionaba un sílex lechoso de buena calidad, y desde allí se trasladaban al campamento donde se finiquitaban. Estos bifaces reflejan una estrategia curatorial (Binford 1979) y multifuncional (Kelly 1988), con un predominio de instrumentos formales (Andrefsky 1998), aunque lascas de filos vivos desprendidas de estos bifaces fueron utilizadas como instrumentos informales de carácter expeditivo. Otras materias primas sugieren una recolección inserta (Binford 1979) y un uso más limitado. 
Estas características reafirman nuestra idea de que estos asentamientos responden a una estrategia cazadora de grupos que descienden desde las serranías del Loa, y tal vez desde la alta Puna, a ambientes más templados, con un patrón de movilidad trashumántica (Núñez 1983; Jackson y Benavente 1994), aprovechando la concentración y permanencia de recursos fluviales y faunísticos (caza de camélidos) en la microcuenca de Chiu Chiu, en momentos en que imperaban condiciones áridas. Es probable que esta situación ambiental generara una ocupación reiterada de estos asentamientos y una consecuente disminución progresiva de la movilidad, y por lo tanto, una mayor territorialidad, como ya se ha planteado para las ocupaciones del Holoceno Medio de la región (De Souza 2004). Estos asentamientos se asocian a campamentos base residenciales de cierta permanencia, que al menos funcionaron sincrónicamente en algunos momentos, lo que sugiere varias bandas asentadas en la microcuenca de Chiu Chiu, como respuesta a las condiciones áridas imperantes.

Con posterioridad al abandono de Isla Grande y Confluencia 2, otros grupos de cazadores ocupan el sitio Loa Oeste 3 y luego Confluencia 1, sin aparentes afinidades con los componentes de los dos primeros sitios mencionados, pues las características puntas de proyectiles lanceoladas con pedúnculo enunciado no están presentes sino que han sido reemplazadas por puntas lanceoladas apedunculadas más pequeñas. Esta vez los asentamientos se sitúan algo más alejados de la confluencia de los ríos Loa y Salado y en cotas más bajas que las ocupaciones anteriores. Loa Oeste 3 se emplaza en la periferia oeste de la cuenca, mientras que Confluencia 1 lo hace en un remanente de terraza hacia el centro de la cuenca. Este cambio en la ubicación de los asentamientos sugiere un advenimiento de mejores condiciones ambientales con mayor humedad, y por lo tanto, la ampliación del forraje en las vegas cercanas.

Por otra parte, la ubicación de Loa Oeste 3 muestra cierta cercanía a los asentamientos anteriores, aunque en una cota más baja. En este sentido, es tentador sugerir una secuencia de ocupación de sur a norte, desde la confluencia de los ríos Loa y Salado: primero Isla Grande, luego Confluencia 2, y posteriormente Loa Oeste 3 , en la medida que mejoran las condiciones ambientales. Consecuentemente, Confluencia 1 se emplaza hacia el centro de la cuenca para controlar el espacio circundante, especialmente las vegas situadas entre el campamento y la confluencia de los ríos Loa y Salado.

Ambos sitios, Loa Oeste 3 y Confluencia 1, son campamentos más extensos y con mayor desarrollo estratigráfico producto de una mayor acumulación de basuras. Persisten las estructuras habitacionales semisubterráneas que aprovechan las irregularidades del calcáreo, pero esta vez se asocian a estructuras pircadas que sugieren campamentos más estables. Las basuras se acumulan en el exterior e interior de los recintos habitacionales, algo más evidente en Confluencia 1 que en Loa Oeste 3. Ambos campamentos muestran al menos tres eventos ocupacionales más densos que los observados en Isla Grande y Confluencia 1. Además, en Loa Oeste 3, se registra un evento ocupacional intermedio con una estructura arquitectónicamente bien formalizada, y sobre ésta un entierro, todo lo cual sugiere mayor estabilidad y permanencia, aunque con cortos eventos de abandono.

Los conjuntos de instrumentos líticos son similares a los de las ocupaciones anteriores, aunque como señalamos, ya no están presentes las puntas con pedúnculo enunciado y aparecen nuevos instrumentos como los microperforadores, cuya frecuencia aumenta progresivamente. Esta nueva categoría se correlaciona con una aparente elaboración intensiva de cuentas de collar así como con una explotación intensiva del cuarzo, materia prima adecuada para la manufactura de perforadores, los cuales están escasamente representados en Isla Grande y Confluencia 2. Las cadenas operativas son más completas para los instrumentos procesados sobre cuarzo, básicamente perforadores. La estrategia tecnológica comienza a manifestar una tendencia a la expeditividad (Nelson 1991), combinada con una estrategia conservada para instrumentos bifaciales y microperforadores.

El creciente aumento de microperforadores podría correlacionarse con la elaboración de cuentas de conchas de moluscos, lo que indica una industria para producir bienes de prestigio destinados al intercambio simbóli$\mathrm{co}$, ya que la notoria presencia de microperforadores y su frecuente reactivado no se correlacionan con el bajo registro de cuentas. 
Esta nueva orientación en la producción lítica destinada posiblemente a la producción de bienes de prestigio, se asocia a la presencia de ocre, guijarros estriados y pulimentados, así como a un aumento en los implementos de molienda. Esto sugiere una diversificación y tal vez una intensificación de la producción alimentaria en asentamientos de mayor tamaño y permanencia asociados a vegas, donde bien pudieron ir cambiando las prácticas cinegéticas hacia un incipiente proceso de domesticación de camélidos, en un contexto sociocultural de mayor agregación social y estabilidad de los asentamientos.

Con posterioridad a Confluencia 1, la ocupación del Cementerio Chiu Chiu se emplaza también en una posición central en la microcuenca pero algo más al norte, cubriendo una extensión mucho mayor $\left(60000 \mathrm{~m}^{2}\right)$, aunque la densidad de los depósitos de ambos sitios es comparable. En el Cementerio Chiu Chiu se registran muros pircados de estructuras habitacionales más amplias y arquitectónicamente más formales. La disposición de las basuras en el exterior e interior de las habitaciones genera montículos sobre las estructuras una vez abandonadas. Entre las basuras se registran osamentas humanas de entierros secundarios, fogones, huesos de camélidos y otros desperdicios, que reflejan una mayor estabilidad y permanencia, así como un mayor número de habitantes.

A lo largo de la secuencia establecida para el Complejo Chiu Chiu (2705-1675 AC) del Arcaico Tardío, con alrededor de 70 sitios, el Cementerio Chiu Chiu marca significativas diferencias respecto a las ocupaciones anteriores, mostrando un creciente proceso de complejización sociocultural. Cambios en el patrón de asentamiento se correlacionan con breves momentos climáticos más húmedos y otros más secos que afectan las vegas cercanas, promoviendo eventos de mayor movilidad trashumántica hacia el curso superior del río Loa como hacia la costa (Núñez 1975; Druss 1976; Mena 1984); lo que establece afinidades muy claras con el asentamiento de Puripica 1 en las quebradas altas de la cuenca de Atacama (Núñez 1983; Núñez et al. 1999), Kalina en el Alto Loa (Berenguer et al. 1985; Berenguer 2004) y con Caleta Huelén 42 en la costa (Zlatar 1983, 1987).

Por otra parte, el instrumental lítico muestra cadenas operativas más completas, una mayor diversidad de ma- terias primas explotadas, predominando el sílex y el cuarzo, este último utilizado preferentemente -al igual que en Confluencia 1- para la producción de microperforadores destinados posiblemente a la elaboración de cuentas de concha como bienes de prestigio para el intercambio. Las puntas de proyectiles son lanceoladas pequeñas y a veces en doble punta, aumentando considerablemente los implementos de molienda. Aparecen también miniaturas de figuras zoomorfas finamente elaboradas en rocas bien pulimentadas, colorante rojo, cuentas de collar y piedras horadadas no registradas en los contextos arqueológicos de los sitios del período anterior.

La diversidad de las materias primas se diversifica a lo largo de la secuencia, mostrando al mismo tiempo un aumento en la utilización de rocas locales y no locales. En el caso del Cementerio Chiu Chiu la diversidad se duplica, lo que podría estar en relación con procesos de trashumacia que permitieron, por una parte, acceder a un mayor número de fuentes secundarias (transportadas) donde se realizó una recolección inserta (Binford 1979); y por otra, a un eventual intercambio con comunidades altoandinas, a través de las cuales se pudo tener acceso a materias primas no locales como la obsidiana (Figura 8).

Los restos textiles de este sitio están elaborados con fibras pelíferas de roedores, guanaco, vicuña, y otros, en fibras de llama; esto sugiere procesos iniciales de domesticación de camélidos y el manejo zootécnico de los mismos (Arias et al. 1991), lo que también se corrobora en el análisis de los restos óseos de camélidos (Cartajena 1993).

En este sentido, es significativa la presencia de arte rupestre de la fase Kalina con representaciones de camélidos asociados a sitios del Complejo Chiu Chiu (Berenguer et al.1985; Berenguer 2004). Una situación similar ocurre con los cazadores de Puripica situados al noreste del Salar de Atacama (Núñez y Santoro 1988), cuyos contextos son análogos a los del Complejo Chiu Chiu (Jackson y Benavente 1994). Todo ello conlleva a un sustancial cambio en la organización social y económica de estas comunidades.

Además, el aumento de los implementos de molienda a lo largo de la secuencia también sugiere cambios significativos (Figura 9), lo que podría estar vinculado con una 


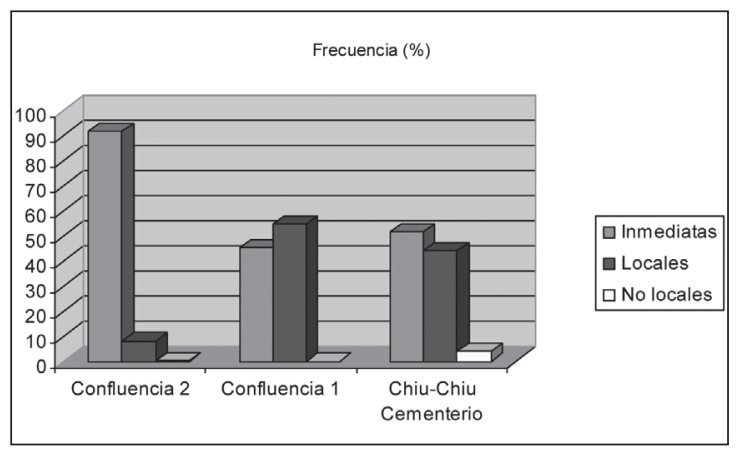

Figura 8. Frecuencia de materias primas a lo largo de la secuencia.

mayor actividad de recolección y/o una incipiente práctica hortícola, como una forma de intensificación de la producción alimentaria.

La ausencia de algarrobo y chañar, incluso en contextos del Formativo Temprano, como en Tulan 54 en la cuenca de Atacama (Núñez et al. 2005) donde también se han registrado abundantes implementos de molienda (Gutiérrez $2006 \mathrm{Ms}$ ), podría estar indicando un intensivo procesamiento de harinas, cuya visibilidad arqueológica es escasa. El procesamiento de harina facilitaría el transporte y conservación (Núñez et al. 2005), disminuyendo el peso inútil en el transporte y permitiendo su consumo diferido.

Por otra parte, en los contextos Chiu Chiu se han registrado semillas y rizomas de juncos (Druss 1976) que tal vez debieron tener algún valor nutricional. La presencia de un fragmento de palo cavador en el Cementerio Chiu Chiu, así como en otros sitios de este complejo (Druss 1976) y la de algunas posibles palas (Gómez 1963), puede estar vinculada a la recolección o a incipientes prácticas hortícolas.

Estos singulares cambios observados en el asentamiento del Cementerio Chiu Chiu y que se anuncian ya

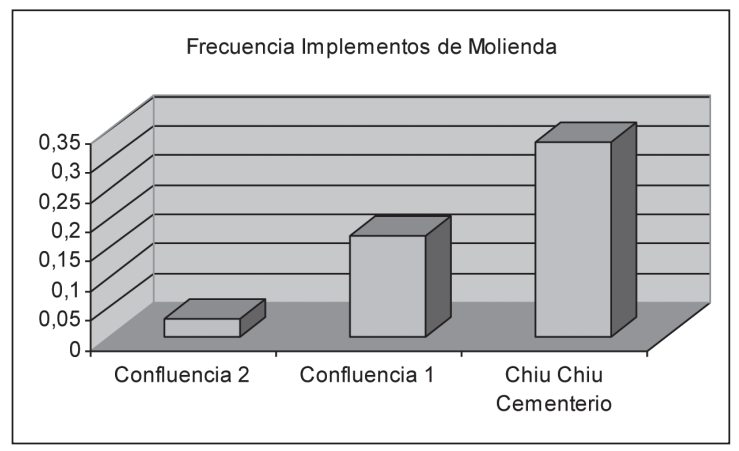

Figura 9. Frecuencia de implementos de molienda a lo largo de la secuencia.

en Confluencia 1, estarían reflejando una mayor estabilidad y permanencia en campamentos bien estructurados, con un control de la microcuenca y territorialidad, junto a una diversificación e intensificación de la producción no solo alimentaria, sino también de bienes de prestigio, los que probablemente fueron destinados al intercambio. Una incipiente domesticación de camélidos y su manejo zootécnico evidencian procesos de complejización socioeconómica en los Andes Centro Sur hacia 4000 AP, iniciando los cambios desde una estructura propia de comunidades cazadoras recolectoras igualitarias a otra de tipo pastoril doméstica no jerarquizada. Esta, se habría consolidado con posterioridad hacia $900 \mathrm{AC}$ en el asentamiento Chiu Chiu 200 (Benavente 1981, 1982), siendo la primera comunidad pastoril del Formativo Temprano en el curso medio del río Loa.

Agradecimientos A los colegas: Carlos Thomas, que estuvo a cargo de las excavaciones del sitio Chiu Chiu; Isabel Cartajena, Gianina Arias y Jaime Ferraz que realizaron trabajos de terreno y análisis de laboratorio. También agradecemos a Diego Salazar y a Andrés Troncoso por los comentarios al manuscrito. 


\section{* Referencias citadas}

ALDUNATE, C., J. BERENGUER, V. CASTRO, L. CORNEJO, J. L. MARTÍNEZ y C. SINCLAIRE, 1986. Cronología y asentamiento en la región del Loa Superior. Universidad de Chile, Santiago.

ANDREFSKY, W., 1998. Lithics: Macroscopic approaches to analysis. Cambridge University Press, Cambridge.

ARIAS, G., A. BENAVENTE y P. GECELE, 1991. Identificación y variabilidad del uso del animal a través de textiles arqueológicos: Contraste con patrones fanéreos actuales. Actas del XII Congreso Nacional de Arqueología Chilena, vol. 2, pp. 151-162. Temuco.

ARNOLD, J. (Ed.), 1996. Emergent complexity. The evolution of intermediate societies. International Monographs in Prehistory. Archaeological Series 9, Ann Arbor, Michigan.

ASCHERO, C. y H. YACOBACCIO, 1998-99. 20 años después: Inca Cueva 7 reinterpretado. Cuadernos del Instituto Nacional de Antropología y Pensamiento Latinoamericano 18: 7-18.

BENAVENTE, A., 1981. Chiu Chiu 200: Un campamento de pastores. Tesis de Grado de Licenciatura en Arqueología y Prehistoria, Departamento de Ciencias Sociológicas y Antropológicas, Universidad de Chile, Santiago.

1982. Chiu Chiu 200: Una comunidad de pastores tempranos en la provincia de El Loa (II región).Actas del IX Congreso Nacional de Arqueología Chilena, pp. 75-94. La Serena.

1989 Ms. Un enfoque arqueozoológico para la identificación de restos óseos de camélidos sudamericanos. Informe Proyecto FONDECYT 792-89, Santiago.

BERENGUER, J., 2004. Cinco milenios de arte rupestre en los Andes atacameños: Imágenes para lo humano, imágenes para lo divino. Boletín del Museo Chileno de Arte Precolombino 9: 75-108.

BERENGUER, J., V. CASTRO, C. ALDUNATE, C. SINCLAIRE y L. CORNEJO, 1985. Secuencia del arte rupestre en el Alto Loa: Una hipótesis de trabajo. En Estudios en arte rupestre, C. Aldunate, J. Berenguer y V. Castro (Eds.), pp. 87-108. Museo Chileno de Arte Precolombino, Santiago.

BETANCOURT, J. L., C. LATORRE, J. A. RECH, J. QUADE y K. A. RYLANDER, 2000. A 22000 year record of monsoonal precipitation from Northern Chile's Atacama Desert. Science 289: 1542-1546.
BINFORD, L., 1979. Organization and formation processes: Looking at curated technologies. Journal of Anthropological Research 35 (3): 255-273.

CARTAJENA, I., 1993. Determinación de restos óseos de camélidos en dos yacimientos del Loa Medio (II región). Tesis para obtener el Título de Arqueóloga. Departamento de Antropología, Facultad de Ciencias Sociales, Universidad de Chile, Santiago.

CARTAJENA, I. e I. CONCHA, 1997. Una contribución a la determinación taxonómica de la familia Camelidae en sitios formativos del Loa Medio. Estudios Atacameños 14: 71-83.

DE SOUZA, P., 2004. Cazadores recolectores del Arcaico Temprano y Medio de la cuenca superior del río Loa: Sitios, conjuntos líticos y sistema de asentamiento. Estudios Atacameños 27: 7-43.

DRUSS, M., 1976. Medioambiente, economía de subsistencia y patrones de asentamientos del Complejo Chiu Chiu (ca.300o2000 AC), norte de Chile. Estudios Atacameños 4: 17-23.

1978. Environment, subsistence economy and settlement pattern of the Chiu Chiu Complex (ca. 2700 to $1600 \mathrm{BC}$ ) of the Atacama Desert, Northern Chile. Ph.D. Thesis, Columbia University.

FERRAZ, J., 1991. Estudio crítico del material lítico del sitio Chiu Chiu Cementerio (Arcaico Tardío): Resultados preliminares. Actas del XII Congreso Nacional de Arqueología Chilena, vol. 2, pp. 129-143. Temuco.

GÓMEZ, I., 1963. Taller lítico de Chiu Chiu, provincia de Antofagasta. Memoria de Título, Facultad de Filosofía y Educación, Universidad de Chile, Santiago.

GOULD, R. y S. SAGGERS, 1985. Lithic procurement in Central Australia: A closer look at Binford's idea of embeddedness in archaeology.American Antiquity 50: 117-135.

GROSJEAN, M., 1994. Paleohidrology of Laguna Lejía (North Chilean Altiplano) and climatic implications for Late glacial times. Paleogeography, Paleoclimatology, Paleoecology 109: 89-100.

GROSJEAN, M. y L. NÚÑEZ, 1994. Lateglacial, Early and Middle Holocene environments, human occupation and resource use in the Atacama (Northern Chile). Geoarchaeology 9: 271- 286. 
GROSJEAN, M., L. NÚÑEZ, I. CARTAJENA y B. MESSERLI, 1997. Mid-Holocene climate and culture change in the Atacama Desert, Northern Chile. Quaternary Research 48: 239-246.

GROSJEAN, M., I. CARTAJENA, M. A. GEYH y L. NÚÑEZ, 2003. From proxy data to paleoclimate: The Mid-Holocene paradox of the Atacama Desert, Northern Chile. Paleogeographic, Paleoclimatodology, Paleoecology 194: 247-258.

GROSJEAN, M., L. NÚÑEZ e I. CARTAJENA, 2005. Paleoindian occupation of the Atacama Desert, Northern Chile. Journal of Quaternary Science 20 (7-8): 643-653.

GUTIÉRREZ, F., 2006 Ms. Primera aproximación al contexto lítico de molienda del sitio Tulan 54. Práctica Profesional, Departamento de Antropología, Facultad de Ciencias Sociales, Universidad de Chile, Santiago.

JACKSON, D., 1990 Ms. Estudio de una estructura habitacional tardía de Chiu Chiu Cementerio, provincia de El Loa. Informe Proyecto FONDECYT 792-89, Santiago.

1993-94. Confluencia 2: Un campamento de cazadores arcaicos del norte de Chile. Revista Chilena de Antropología 12: 113-122.

JACKSON, D. y A. BENAVENTE, 1994. Secuencia, cambios y adaptaciones de los cazadores recolectores de la microcuenca de Chiu Chiu, provincia de El Loa. Chungara 26 (1): 49-64.

KELLY, R. L., 1988. The three sides of a biface. American Antiquity 53: 717-734.

LAVALLÉE, D., 2006. Secuencias y consecuencias de algunos procesos de neolitización en los Andes Centrales. Estudios Atacameños 32:35-41.

MENA, F., 1984. Patrones de movilidad en el Arcaico Tardío; II región. Estudios Atacameños 7: 26-41.

MELTZER, D., 1989. Was stone exchanged among Eastern North American paleoindians. En Eastern Paleoindian lithic resource use, C. J. Ellis y D. Lothrop (Eds.), pp. 11-39. Westview Press, Boulder.

NELSON, M. C., 1991. The study of technological organization. En Archaeological method and theory, vol. 3, M. Schiffer (Ed.), pp. 57100. The University of Arizona Press, Tucson.

NÚÑEZ, L., 1975. Dinámica de grupos precerámicos en el perfil costa-altiplano, norte de Chile. Estudios Atacameños 3: 59-74.

1976. Registro regional de fechas radiocarbónicas del norte de Chile. Estudios Atacameños 4: 74-123.
1983. Paleoindio y Arcaico en Chile: Diversidad, secuencia y procesos. Serie Monográfica Cuicuilco 1, Escuela Nacional de Antropología e Historia, México D.F.

1992. Ocupación Arcaica en la Puna de Atacama: Secuencia, movilidad y cambio. En Prehistoria sudamericana: Nuevas perspectivas, B. Meggers (Ed.), pp. 283-307. Taraxacum, Washington D.C.

NÚÑEZ, L.y C. SANTORO, 1988. Cazadores de la Puna Seca y Salada del Área Centro Sur Andina (norte de Chile). Estudios Atacameños 9:11-60.

NÚÑEZ, L., M. GROSJEAN, B. MESSERLI y H. SCHRELIER, 199596. Cambios ambientales holocénicos en la Puna de Atacama y sus implicancias paleoclimáticas. Estudios Atacameños 12:31-40.

NÚÑEZ, L., M. GROSJEAN e I. CARTAJENA, 1999. Un ecorrefugio oportunístico en la Puna de Atacama durante eventos áridos del Holoceno Medio. Estudios Atacameños 17: 125-174.

2001. Human dimensions of Late Pleistocene/Holocene arid events in Southern South America. En Interhemispheric climate linkages, V. Markgraf(Ed.), pp. 105-117. Academic Press, San Diego.

2002. Human occupations and climate change in the Puna de Atacama, Chile. Science 298: 821-824.

NÚÑEZ, L., I. CARTAJENA, C. CARRASCO y P. DE SOUZA, 2005. El templete de Tulán y sus relaciones formativas panandinas (norte de Chile). Bulletin de l'Institut Français d'Études Andines 34 (3): 299-320.

NÚÑEZ, L., I. CARTAJENA, C. CARRASCO, P. DE SOUZA y M. GROSJEAN, 2006. Emergencia de comunidades pastoriles formativas en el sureste de la Puna de Atacama. Estudios Atacameños 32: 93-117.

OLIVERA, D., 1997. La importancia del recurso Camelidae en la Puna de Atacama entre 10000 y 500 años AP. Estudios Atacameños 14: 29-41.

ORELLANA, M., 1965. Informe de la primera fase del proyecto arqueológico Río Salado. Antropología 3: 81-117.

1971. Informe de las excavaciones de Loa Oeste. Boletín de Prehistoria de Chile $3(4): 3-25$.

PRICE, D. y J. BROWN, 1985. Prehistoric hunter-gatherers, emergence of cultural complexity. Academic Press, San Diego.

RECH, J., J. QUADE y J. BETANCOURT, 2002. Late Quaternary paleohydrology of the central Atacama Desert (Lat $22^{\circ}-24^{\circ} \mathrm{S}$ ), Chile. Geological Society of America Bulletin 114 (2):334-348. 


\section{Donald Jackson, Antonia Benavente}

REES, C.y P. DE SOUZA, 2004. Producción lítica durante el período Formativo en la subregión del río Salado. Chungara, Revista de Antropología Chilena, vol. especial, pp. 453-465.

RICK, J., 1983. Cronología, clima y subsistencia en el Precerámico peruano. Ediciones del Instituto Andino de Estudios Arqueológicos, Lima.

SERRACINO, G. y C. THOMAS, 1971. Excavaciones del yacimiento Confluencia 1. Boletín de Prehistoria de Chile 4:49-68.

SINCLAIRE, C., 1985. Dos fechas radiocarbónicas del Alero Chulqui, río Toconce: Noticia y comentario. Chungara 14: 71-79.

WHEELER, J., E. PIRES-FERREIRA y P. KAULICKE, 1977. Domesticación en los Andes durante el Precerámico: Un modelo. Journal de la Société des Américanistes XIV: 155-165.
YACOBACCIO, H., 2000. Cazadores complejos y domesticación de camélidos. En El uso de los camélidos a través del tiempo, G. Mengoni, D. Olivera y H. Yacobaccio (Eds.), pp. 261-282. Editorial del Tridente, Buenos Aires.

ZLATAR, V., 1983. Replanteamiento sobre el problema Caleta Huelén 42. Chungara 10:21-28.

1987. Un yacimiento precerámico y su problemática desde la perspectiva de sus recintos habitacionales. Hombre y Desierto 1: $1-36$. 